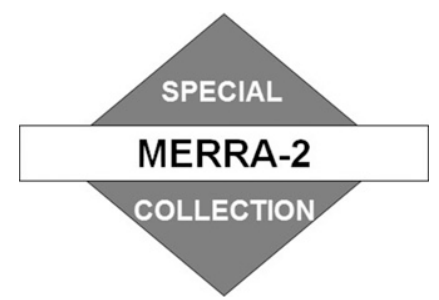

\title{
An Assessment of NASA's GMAO MERRA-2 Reanalysis Surface Winds
}

\author{
D. CARvalho \\ Global Modeling and Assimilation Office, NASA Goddard Space Flight Center, Greenbelt, and Goddard Earth Sciences \\ Technology and Research, Universities Space Research Association, Columbia, Maryland
}

(Manuscript received 15 March 2019, in final form 29 July 2019)

\begin{abstract}
The quality of MERRA-2 surface wind fields was assessed by comparing them with 10 years of measurements from a wide range of surface wind observing platforms. This assessment includes a comparison of MERRA-2 global surface wind fields with the ones from its predecessor, MERRA, to assess if GMAO's latest reanalyses improved the representation of the global surface winds. At the same time, surface wind fields from other modern reanalyses-NCEP-CFSR, ERA-Interim, and JRA-55-were also included in the comparisons to evaluate MERRA-2 global surface wind fields in the context of its contemporary reanalyses. Results show that MERRA-2, CFSR, ERA-Interim, and JRA-55 show similar error metrics while MERRA consistently shows the highest errors. Thus, when compared with wind observations, the accuracy of MERRA-2 surface wind fields represents a clear improvement over its predecessor MERRA and is in line with the other contemporary reanalyses in terms of the representation of global near-surface wind fields. All reanalyses showed a tendency to underestimate ocean surface winds (particularly in the tropics) and, oppositely, to overestimate inland surface winds (except JRA-55, which showed a global tendency to underestimate the wind speeds); to represent the wind direction rotated clockwise in the Northern Hemisphere (positive bias) and anticlockwise in the Southern Hemisphere (negative bias), with the exception of JRA-55; and to show higher errors near the poles and in the ITCZ, particularly in the equatorial western coasts of Central America and Africa. However, MERRA-2 showed substantially lower wind errors in the poles when compared with the other reanalyses.
\end{abstract}

\section{Introduction}

Analyses are a combination of global numerical weather prediction (NWP) model fields and observations, being currently the best estimate of the real atmospheric state at a given time. Information from both sources is combined in a physically consistent manner by a data assimilation system (DAS) to produce an optimized balance between NWP models and real atmospheric observations (Kalnay 2003). Reanalyses basically mimic an operational analysis process but are run for a long period of time using unchanging NWP model and DAS, providing a consistent long-term global meteorological record without the changes and discontinuities inherent to operational analyses systems, aside from changes in the observation network. They have become a cornerstone not only for meteorological, atmospheric, and climatic research activities, but also for other lines of

\footnotetext{
Corresponding author: David Carvalho, david.carvalho@nasa. gov
}

research and business such as agriculture, renewable energies, air quality, and risk-management applications.

By strongly influencing surface weather conditions, near-surface winds are one of the meteorological fields that most affect and influence human activity and wellbeing. They play a central role in lower troposphere mixing, dispersion, and transport and are also responsible for the production of renewable energies such as wind and wave-derived energy (by acting as one of the main forcing mechanisms of ocean waves). Thus, surface wind data provided by reanalyses have become very useful for a wide range of research and business activities.

In the recent past, several new generation global reanalyses that encompass the modern satellite era have been produced: the Climate Forecast System Reanalysis (CFSR) by the National Centers for Environmental Prediction (NCEP); ERA-Interim (ERA-I) by the European Centre for Medium-Range Weather Forecasts (ECMWF); the Japanese 55-Year Reanalysis (JRA-55) by the Japan Meteorological Agency (JMA); and the Modern-Era Retrospective Analysis for Research and 
TABLE 1. Main characteristics of the reanalyses used.

\begin{tabular}{llcccc}
\hline \hline Reanalysis & Horizontal resolution & Vertical levels & Temporal resolution & Data assimilation system type & Time coverage \\
\hline MERRA & $0.5^{\circ}$ lat $/ 0.667^{\circ}$ lon & 72 & Hourly & 3D-Var & 1979-March 2016 \\
MERRA-2 & $0.5^{\circ}$ lat $/ 0.625^{\circ}$ lon & 72 & Hourly & 3D-Var & 1980-present \\
ERA-Interim & $0.75^{\circ}$ lat/lon & 60 & 4 times/day & 4D-Var & 1979-present \\
CFSR & $0.5^{\circ}$ and $0.312^{\circ}$ lat/lon & 64 & Hourly & 3D-Var & 1979-present \\
JRA-55 & $0.56^{\circ}$ lat/lon & 60 & 4 times/day & 4D-Var & 1958-present \\
\hline
\end{tabular}

Applications (MERRA) by the National Aeronautics and Space Administration (NASA) Global Modeling and Assimilation Office (GMAO). Although MERRA was qualitatively in line with its contemporaneous reanalyses (e.g., Decker et al. 2011), several known issues and deficiencies were detected (e.g., Bosilovich et al. 2011; Reichle et al. 2011; Rienecker et al. 2011; Robertson et al. 2011). In addition, MERRA heavily relied on a small set of instruments as main sources of assimilated observations, which are close to or even beyond their expected lifetime (e.g., satellites NOAA-18 and $A q u a$ as the only sources of hyperspectral infrared and afternoon-orbit microwave radiances). Because of these limitations, the Modern-Era Retrospective Analysis for Research and Applications, version 2 (MERRA-2) arose as a replacement for MERRA.

The aims of this work are twofold: 1) to assess the improvements of MERRA-2 representation of the global surface winds over its predecessor MERRA and 2) to compare MERRA-2 with its contemporary reanalyses to evaluate whether they are in line with the other reanalyses' surface winds. Several papers regarding the validation, analysis, and assessment of a wide panoply of MERRA-2 atmospheric parameters and processes are available in the American Meteorology Society Journal of Climate MERRA-2 Special Collection (http:// journals.ametsoc.org/topic/merra-2), which provides an overview of the MERRA-2 system performance and on other key issues related to the large-scale and regional variations in weather and climate over the past few decades, including extreme precipitation events, the structure of major El Niño events, energy flux, aerosols, ozone, and many more. This work aims to contribute to this collection by filling the gap in terms of the evaluation of MERRA-2 representation of the global surface wind fields.

Although a validation of MERRA-2 surface wind fields has not been carried out until now, a few published studies validate and/or compare MERRA-2 higher-altitude winds with other reanalyses. Manney et al. (2017) compared the upper tropospheric/lower stratospheric jets and tropopauses from MERRA, MERRA-2, ERA-I, CFSR, and JRA-55, finding substantial differences among the different reanalyses. Friedrich et al. (2017) compared stratospheric winds from balloon observations with MERRA, MERRA-2, CFSR, and ERA-I, reporting that MERRA-2 winds were closest to the measurements. Hoffmann et al. (2017) compared temperatures and horizontal winds of several reanalyses (ERA-I, MERRA, MERRA-2, and the NCEP-NCAR reanalysis) in the Antarctic lower stratosphere, concluding that MERRA-2 stratospheric winds showed the lowest biases. Other studies compared reanalysis surface winds (including MERRA, but not MERRA-2) with measurements and reported that although MERRA surface winds were generally on par with the ones from its contemporary reanalyses, they showed a somewhat poorer performance, highlighting the need for improvement in future releases of GMAO reanalyses (e.g., Alvarez et al. 2014; Carvalho et al. 2014a,b,c).

This study is organized as follows: section 2 describes all the wind datasets considered in this work (reanalyses and wind observations) and the methods used, section 3 presents the results and discussion, and section 4 summarizes the main conclusions.

\section{Data and method}

\section{a. Reanalysis data}

Table 1 summarizes the main characteristics of the reanalyses used in this study.

MERRA (Rienecker et al. 2011) was produced by NASA's GMAO in 2011, aiming to place the wealth of NASA's EOS satellites measurements into a climate context-unified dataset and to improve the hydrologic cycle of NASA's earlier generations of reanalyses. MERRA was generated with the Goddard Earth Observing System (GEOS) atmospheric global circulation model (AGCM) and DAS, version 5 (GEOS-5 DAS; Rienecker et al. 2008). MERRA fields are only available at the GEOS-5 model levels, given that the lowest GEOS-5 model level is located at approximately 80 $90 \mathrm{~m}$ above ground level (AGL). As such, surface meteorological fields such as $2-\mathrm{m}$ temperature and $10-\mathrm{m}$ wind (among others) are not available in the reanalyzed fields collection. They are, however, available as diagnostic fields where incremental analysis update (IAU; Bloom et al. 1996) is used to gradually adjust the model 
state toward the observed state. Thus, MERRA surface wind data used in this work consist of continuous 6-h model runs with an extra forcing term, the analysis tendencies, to force the AGCM solution toward the DAS solution.

MERRA-2 (Gelaro et al. 2017) is the successor of MERRA, adding to its observing system many observation types not available to MERRA such as several new-generation satellite data, ozone and aerosol data assimilation, improved stratosphere, cryosphere, and land surface representation, reduction of spurious trends and jumps related to changes in the observing system, reduced biases and imbalances in the water cycle, and the use of precipitation observations to force the land surface (Gelaro et al. 2017). MERRA-2 was built from a revised version of the GEOS-5 DAS [see Molod et al. (2015) for details about the evolution of the GEOS5-DAS system from MERRA to MERRA-2], which performs computations on a cubed-sphere global grid that allows for a better representation of dynamical processes in high latitudes. MERRA-2 is one of the few global reanalyses that assimilates data from the entire constellation of NASA EOS satellites (Gelaro et al. 2017). Similarly to MERRA, MERRA-2 surface wind data used in this study consist of the hourly IAU file collection.

ERA-Interim (hereinafter ERA-I; Dee et al. 2011) is produced by ECMWF and uses a four-dimensional variational analysis (4D-Var) assimilation system. ERA-I came as the replacement for ERA-40 for the data-rich modern era (1990 to the present), with increased horizontal resolution and updated atmospheric model when compared with ERA-40.

The NCEP-CFSR (hereinafter simply CFSR; Saha et al. 2010) is based on a coupled atmosphere-oceanland surface-sea ice system (although the actual reanalysis is uncoupled), using a 3D-Var assimilation system. Besides the native resolution of $0.5^{\circ}$ in latitude and longitude, for surface winds CFSR data are also available at a higher horizontal resolution of $0.312^{\circ}$ in latitude and longitude. In this study, all CFSR surface wind data were taken from the higher-resolution collection. Unlike MERRA and MERRA-2, CFSR hourly surface wind fields are purely $1-6-\mathrm{h}$ forecasts and do not contain any influence or forcing from the assimilated observations, besides in their initialization.

The JRA-55 (Kobayashi et al. 2015), is produced by JMA. Relative to the previous JMA reanalysis, JRA-25, JRA-55 uses a more advanced data assimilation scheme (4D-Var vs 3D-Var), increased model resolution, and a new variational bias correction for satellite radiances and radiosonde temperatures, along with the addition of several observational data sources.
All reanalyses considered here assimilate practically the same types of surface wind observations: ships, drifting buoys, and scatterometers (QuikSCAT and ERS-1 and -2). In addition to these observations, data from SSM/I and SSMIS microwave radiometer wind speeds are assimilated by MERRA-2, JRA-55, and ERA-I, in the latter in the form of radiances according to Dee et al. (2011); ASCAT scatterometer ocean surface winds are assimilated by MERRA-2 and JRA-55; and WindSAT polarimetric microwave radiometer ocean surface wind vectors are assimilated by MERRA-2 and CFSR. Unlike the other reanalyses, MERRA and MERRA-2 also assimilate ocean surface winds from some moored buoys.

\section{b. In situ wind measurements}

All reanalyses' surface wind data are compared with a decade (2001-10) of in situ wind measurements collected at different geographical areas, including inland and offshore regions (Fig. 1). Red or blue dots depict the location of measuring sites located in ocean or land areas, respectively.

The equatorial ocean measuring sites belong to the Tropical Atmosphere Ocean and the Triangle TransOcean Buoy Network (TAO/TRITON, in the Pacific Ocean; 12 buoys), and to the Prediction and Research Moored Array in the Tropical Atlantic (PIRATA, in the Atlantic Ocean; 7 buoys) arrays. These buoys are moored in the open ocean and report hourly measurements of the wind speed and direction at $4 \mathrm{~m}$ above mean sea level (MSL). In addition, offshore wind observations collected by eight coastal buoys moored off the Spanish Atlantic Ocean and Mediterranean Sea coasts are also used. The Spanish buoys are operated and maintained by the Puertos del Estado Spanish Agency and measure the wind speed and direction hourly at $3 \mathrm{~m}$ MSL. Wind data from all the reanalyses are then taken at the closest grid points to the buoy sites (nearest neighbor).

Given that the buoys' wind measurement instruments are placed at 3 or $4 \mathrm{~m}$ MSL and that the reanalyses' surface winds are referenced to $10 \mathrm{~m}$ MSL, it is necessary to extrapolate the buoy wind data from $3-4$ to $10 \mathrm{~m}$ MSL. Ideally, such extrapolation should be done with methods that account for the atmospheric stability like the Monin-Obukhov (Monin and Obukhov 1954) or the Liu and Tang (Liu and Tang 1996) methods. However, these require measurements of the temperature, heat fluxes, and friction velocity, which are not available for the buoys considered here. Thus, the logarithmic wind profile, a simpler method to extrapolate the buoy measurements that only requires wind speed and direction measurements but assumes a neutral atmosphere, was 


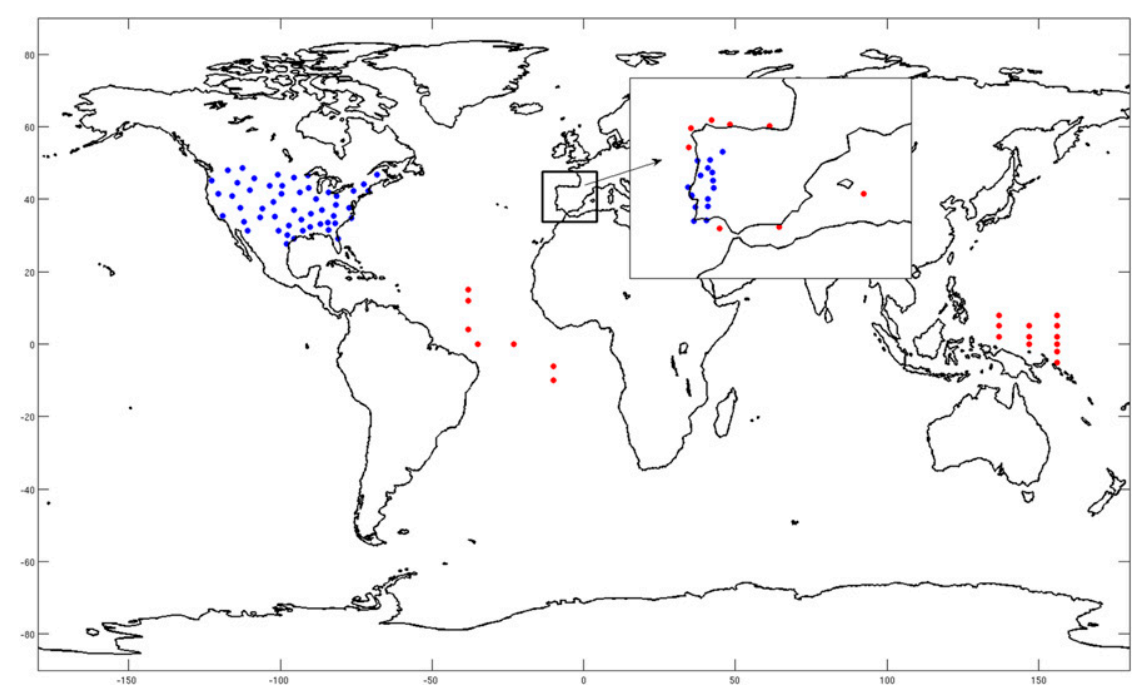

FIG. 1. In situ wind measurement site locations (blue: onshore; red: offshore).

used. Several studies (e.g., Bourassa et al. 2003; Chelton and Freilich 2005; Kara et al. 2008; Mears et al. 2001) showed that differences between stability-dependent and neutrally stable winds are low over the global ocean, rarely exceeding $0.5 \mathrm{~m} \mathrm{~s}^{-1}$. Moreover, since the extrapolation is done for a small height difference, from 3-4 to $10 \mathrm{~m}$ MSL, over a surface with low roughness, it is expected that differences between measured and extrapolated winds are not significant. In addition, by using 10 years of wind data, it is reasonable to assume that the prevalent atmospheric stratification over the global ocean is close to neutral (Carvalho et al. 2014a).

The inland in situ wind measurements were taken at 68 weather stations scattered across the continental United States (52 stations) and Portugal (16 stations). The U.S. wind measurements were obtained from NOAA's National Climatic Data Center (NCDC) and consist of daily wind speed and direction measurements collected at $10 \mathrm{~m}$ AGL. The Portuguese weather stations are operated by the Portuguese Institute for Sea and Atmosphere (IPMA), and the wind observations, hourly wind speed, and direction records collected at $10 \mathrm{~m}$ AGL were provided by the Meteorology and Climatology group of the University of Aveiro (Portugal). The $10-\mathrm{m}$ wind data from all of the reanalyses were taken at these 68 inland sites by performing horizontal bilinear interpolations from the reanalysis grids.

One important consideration about the wind measurements used to validate the reanalyses surface winds is whether they are independent observations (i.e., whether or not they were assimilated by the reanalyses). According to Rienecker et al. (2011) and Gelaro et al. (2017), MERRA and MERRA-2 do not assimilate surface winds from land stations (only surface pressure) or from the PIRATA buoys or the Spanish buoys used in this study. However, they do assimilate ocean surface winds from some TAO buoys. Data from the TAO buoys assimilated in MERRA and MERRA-2 were thus discarded, and only TAO buoys measurements not used in MERRA/MERRA-2 assimilation were used in the comparisons. JRA-55, NCEP-CFSR, and ERA-I only assimilate surface pressure from moored buoys and land stations (Kobayashi et al. 2015; Dee et al. 2011; Saha et al. 2010). Thus, none of the buoys or inland stations measured winds used in this study were assimilated by the reanalyses considered here.

\section{c. Method of comparison}

In section 3a all reanalyses' winds were evaluated by means of a direct comparison with the offshore and inland in situ wind measurements. 10 years (2001-10) of reanalyses and observations were considered and the following statistical metrics were used to assess the differences between the reanalyses and measured winds: the root-mean-square error (RMSE), the bias and the absolute bias, the standard deviation of the error (STDE), and correlation coefficients $\left(R^{2}\right)$ for the wind speed and direction, considering the wind data records that passed quality control and are simultaneous between each reanalysis and the observations. For the wind direction, which is a circular variable, the statistical error metrics were computed using circular statistics formulas as described in Fisher (1995) and Jammalamadaka and SenGupta (2001).

Section $3 \mathrm{~b}$ shows global horizontal maps of $10-\mathrm{m}$ wind speed, direction, and $U$ and $V$ RMSE and bias, computed for each reanalysis using as reference wind observations collected by a combination of several surface 
TABLE 2. Surface wind observation types considered in the wind observational grid.

\begin{tabular}{llc}
\hline \multicolumn{1}{c}{ Data type } & \multicolumn{1}{c}{ Platform type } & Availability \\
\hline Surface marine $U$ and $V$ & Ships, buoys, C-MAN, and tide gauges & $2001-10$ \\
Surface land $U$ and $V$ & METAR (aviation report) stations (fixed and mobile) & $2001-10$ \\
Surface marine $U$ and $V$ & ATLAS buoys (moored) & $2001-10$ \\
Surface marine wind speed (superobbed) & Satellite (SSM/I, SSMIS) & $2001-09$ \\
Surface marine and land $U$ and $V$ & METAR (land); ships, buoys, C-MAN, and tide gauges (ocean) & $2001-10$ \\
Surface marine $U$ and $V$ (superobbed) & Satellite (QuikSCAT) & $2001-09$ \\
Surface marine $U$ and $V$ & Satellite (ERS) & $2001-10$ \\
Surface marine $U$ and $V$ (superobbed) & Satellite (WindSAT) & $2003-10$ \\
Surface marine $U$ and $V$ & Satellite (ASCAT) & $2001-10$ \\
Surface marine $U$ and $V$ & Buoys (drifting) & $2001-10$ \\
\hline
\end{tabular}

winds observation types. Verifying 10-yr global grids of 6-hourly $10-\mathrm{m}$ wind speed, direction, and $U$ and $V$ observations were made for each reanalysis to match each reanalysis's horizontal resolution. Each 6-hourly gridpoint wind observation is a spatial average between all collocated (in space and time) observations collected in the area corresponding to the grid point in that 6-h period. Table 2 details all surface wind observation types that were considered in the computation of these observational grids. The wind observations are part of the NCEP PREPBUFR (Prepared Binary Universal Form for the Representation of Meteorological Data) reports used by its Global Data Assimilation System (GDAS) and also by the GMAO DAS.

NCEP's PREPBUFR data are the major source of conventional observational data for assimilation into the MERRA-2 and CFSR reanalyses, being subjected to several quality control (QC) checks. Details of the QC performed in NCEP's PREPBUFR data can be found on the Internet (http://www.emc.ncep.noaa.gov/mmb/ data_processing/prepbufr.doc/document.htm and http://www.emc.ncep.noaa.gov/mmb/data_processing/ data_dumping.doc/document.htm) and also in McCarty et al. (2016). The observational grids were built using the GMAO Gridded Innovations and Observations (GIO) software package (Bosilovich et al. 2015), which offers the possibility to produce gridded observations binned to the native reanalysis grid in space and time, for each observing platform and observations type, as well as instrument and channel. If multiple observations, from the same or a different observing system/platform, are present in the same grid point, they are spatially averaged to create a single observation value at each grid point.

Some of the wind observation types included in the observational grids are used by all the reanalyses in their data assimilation process (ships, drifting buoys, scatterometers, and other satellite-based data types), while other types are usually not (all surface land and some marine winds, such as moored buoys). Even if some of the observation types used to build the observational grids are assimilated by the reanalyses, the fact that several observations are averaged to a single value in each grid point for a given time and location makes this wind observational grid differ from the actual observations assimilated in the reanalyses and, thus, can be considered as sufficiently independent for comparison purposes. Another issue to take into account is the representativeness of the wind observations when compared with reanalyses data, since the latter are fundamentally best interpreted as gridbox averages. While for some areas (particularly over open ocean areas) the wealth of available satellite-derived ocean surface winds observations allows the use of several observations to carry out the averaging, other areas of the globe do not have available this wealth of surface wind observations and the obtained averages might contain some representativeness errors. Nevertheless, the analysis presented in section $3 \mathrm{~b}$ focuses mainly in global/synoptic spatial scales, being expected that across such large scales representativeness issues of some observational grid points are not a major source of errors.

\section{Results and discussion}

\section{a. Comparison with in situ wind observations}

The reanalysis winds are first compared with in situ wind measurements collected at the offshore and inland sites, as described in section $2 \mathrm{~b}$. Table 3 (also see Table A1 in appendix A) depicts the statistical comparison between the reanalyses and in situ wind observations in terms of the mean values of each error metric for all sites, divided by groups: the PIRATA, TAO/ TRITON, and Spain buoys, and the U.S. and Portugal inland stations. The last group of each table (labeled Mean) shows the mean values of each error metric for all site groups.

For each error metric mean, the smallest error is in boldface font for clarity. In Table 3 all available reanalysis and observation data are used (hourly and 


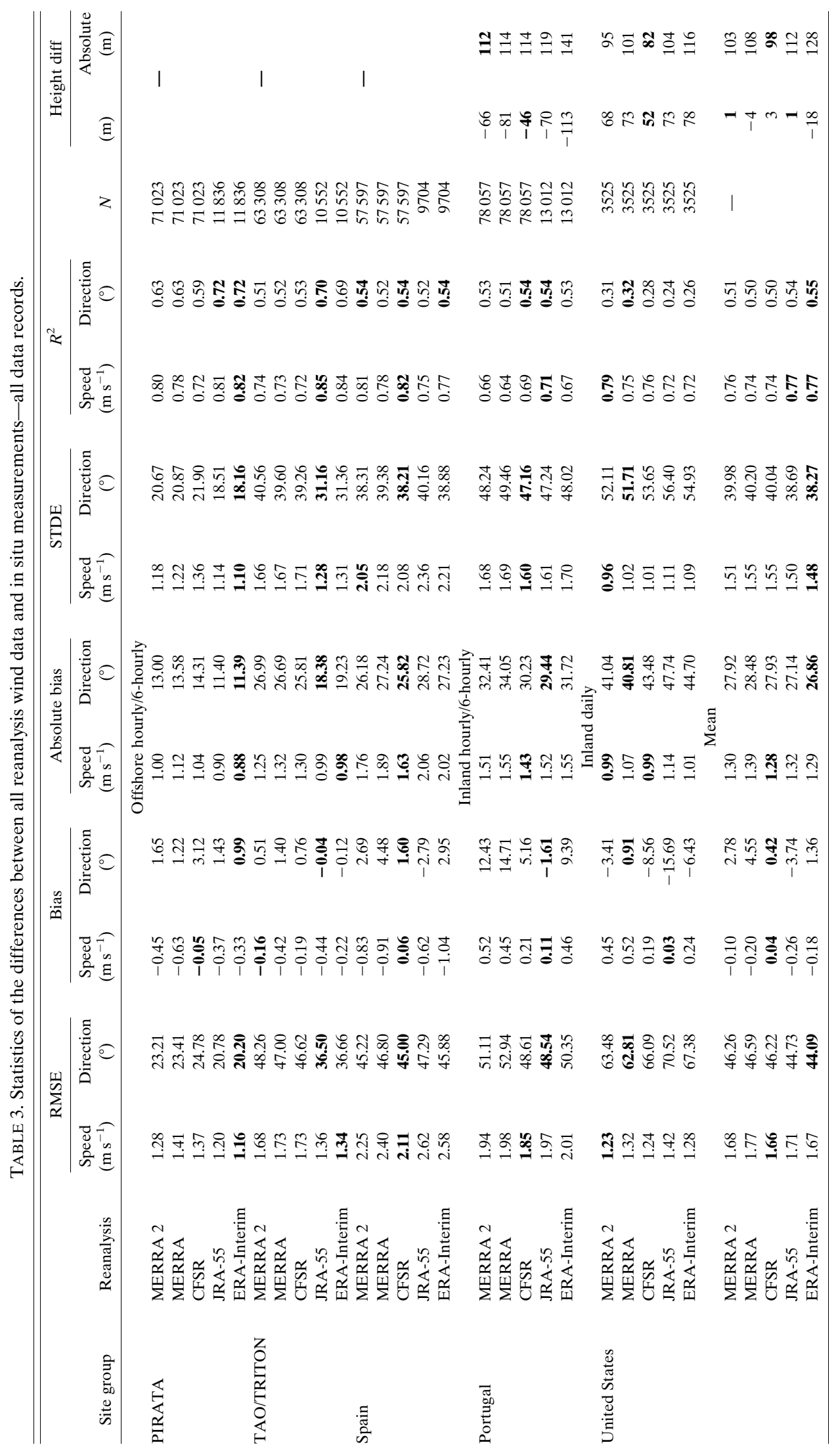


6-hourly). [In contrast, in Table A1 only the temporally simultaneous records among all (reanalyses and wind observations) are used, corresponding to the 6-hourly data records.] Given the influence that the topography has on surface winds, the last two columns of each table show, for the inland sites only, the difference between the real and grid-represented terrain height for all reanalyses. The absolute height difference was computed using the absolute values of the height differences to avoid mutual cancellations between the different sites and thus mask high(er) differences in the mean values.

The first striking feature in Table 3 is that there is a clear improvement from MERRA to MERRA-2 in the representation of the surface wind fields, since for all error metrics presented MERRA-2 shows lower errors than MERRA. However, CFSR and ERA-I are the ones with the lowest mean errors, although the differences with JRA-55 and MERRA-2 are small. Thus, all reanalyses show similar error metrics, with the exception of MERRA, which has a tendency to show the highest errors, and a tendency to underestimate ocean surface winds (negative biases) and overestimate inland surface winds (positive biases).

Analyzing the results by site groups, for PIRATA buoys ERA-I shows the lowest errors for all metrics except for the wind speed bias, where CFSR has the lowest one. JRA-55 follows very closely ERA-I for these sites in terms of error metrics. For the TAO/TRITON buoys, ERA-I and JRA-55 show the lowest errors and very similar performance, except for the wind direction bias where MERRA-2 has the lowest value. For the Spanish buoys, CFSR has the lowest errors for all metrics except for the wind speed STDE, where MERRA-2 has the lowest value (but very similar to the CFSR one). For the Portuguese inland stations, CFSR and JRA-55 show the lowest errors while for the U.S. land stations MERRA and MERRA-2 seem to be the ones with the lowest errors. Note that the error metrics pertaining to the wind direction over U.S. inland sites should be interpreted with care because the wind direction observations from U.S. meteorological stations available from NOAA NCDC are not the hourly mean wind direction, but the direction of the strongest 5 -s wind gust detected in each hourly period (https://www1.ncdc.noaa.gov/ pub/data/cdo/documentation/LCD_documentation.pdf).

It is clear that the highest errors are seen in the Spanish coastal buoys and inland Portugal. These two areas are located in ocean-land transition zones (most of the Portuguese stations here considered are located very close to the Portuguese Atlantic coast), which are characterized by strong land-sea gradients and discontinuities (thermal, pressure, orography, roughness length) that are usually challenging for NWP models to accurately represent (particularly for global ones with horizontal resolutions on the order of $75-50 \mathrm{~km}$ ). CFSR's best overall performance in these sites can be related to their highest horizontal resolution (Table 1). It is also visible that CFSR and MERRA-2 are the reanalyses that show the best representation of the inland sites topographies (lowest differences in terms of the sites' terrain height), which might explain, at least partially, their best performance over land. Land surface winds are heavily influenced by the local terrain topography and land use, which are usually poorly represented in global reanalyses. Thus, CFSR's and MERRA-2's higher spatial resolution allows a better representation of the terrain characteristics, thus improving the modeling of surface winds.

In comparing Tables 3 and A1, it is noticeable that the hourly reanalyses MERRA and MERRA-2 show similar error metrics when considering their hourly or 6-hourly data, but CFSR shows strikingly higher errors when only its 6-hourly $(0000,0600,1200$, and 1800$)$ wind records are considered. As previously mentioned, unlike the other reanalyses, CFSR $10-\mathrm{m}$ wind data records corresponding to the $0000,0600,1200$, and 1800 synoptic times consist of 6-h forecasts, which might explain why these wind records show considerably higher errors. Obviously, ERA-I and JRA-55 show the same error values since they only have available 6-hourly records (the wind records used in Tables 3 and A1 are the same). MERRA and MERRA-2 hourly wind records, unlike the other reanalyses, are only available at the middle of the hourly bins $(0030,0130, \ldots, 0630, \ldots, 1230$ UTC, etc.), which might introduce some phase differences and account for a part of their errors.

\section{b. Global RMSE and bias maps}

Figure 2 shows global wind speed and direction RMSE spatial maps for all reanalyses. Each reanalysis RMSE grid was computed using as reference the observational grid described in section $2 c$, considering 6hourly $(0000,0600,1200$, and 1800 UTC) $10-\mathrm{m}$ wind speed and direction data for 2001-10. (Figure B1 in appendix B shows the same information, but for the $U$ and $V$ wind components.)

According to Fig. 2 (and Fig. B1), the spatial patterns and variations of the RMSE values appear to be very similar among all reanalyses for the wind speed, wind direction, and zonal $(U)$ and meridional $(V)$ wind components. This is somewhat expected due to their similar physical assumptions and assimilation of similar observational databases. All reanalyses show the highest RMSEs near the poles, agreeing with the findings of Chaudhuri et al. (2014) and Francis (2002) that showed 

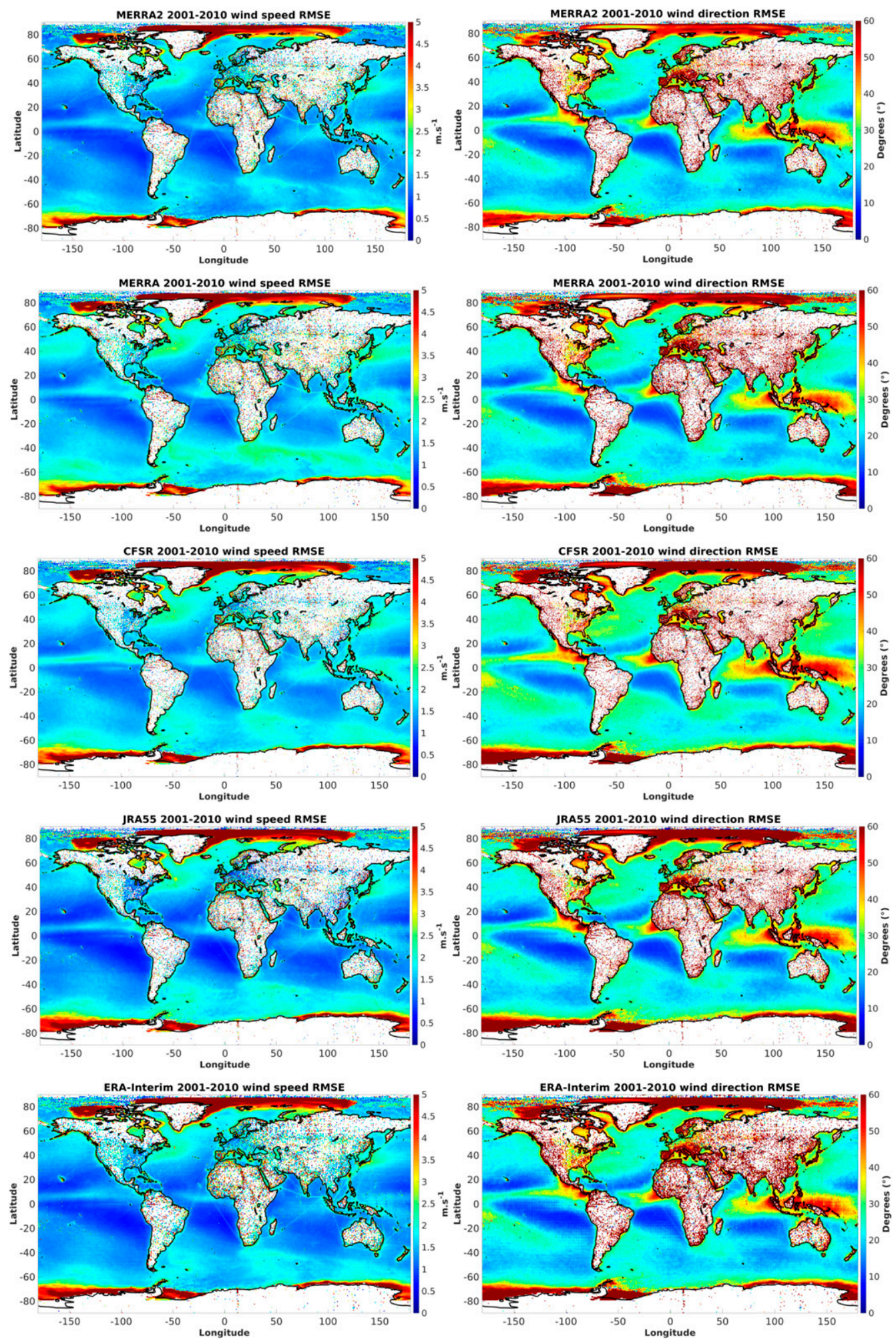

FIG. 2. Wind speed and direction global RMSE maps for the 2001-10 period. 
large discrepancies in the surface zonal and meridional winds between reanalyses and buoy/satellite-retrieved winds for the Arctic. At polar areas, the main sources of wind observations for the observational grid consist of retrievals from satellite-borne instruments: scatterometers (QuikSCAT, ASCAT, ERS) and radiometers (WindSAT, SSM/I, SSMIS). Ocean areas with a tendency to show significant sea ice fractions most likely negatively impact both scatterometer and radiometer retrievals: for radiometers, the ice is more emissive than ice free water and can mimic clouds or rain, artificially increasing the wind speed retrievals; for scatterometers the backscatter from ice is in the range of the backscatter from a rough ocean, but is not related to the wind field. Because at high-latitude areas there are typically significant fractions of sea ice, these errors could be due to the poor quality of the observations. However, all scatterometer data included in the observational grids were obtained from NCEP's PREPBUFR files and, thus, were subjected to QC procedures that discard wind retrievals flagged with poor quality, such as the ones taken at ocean areas with significant fractions of sea ice, rain, and land. Additionally, although polar areas tend to show significant sea ice fractions mainly above $80^{\circ} \mathrm{N} / \mathrm{S}$ in winter periods, they do show a majority of ice-free ocean surface at late summer/early fall periods. Last, as can be seen in Table 1, retrieved winds from QuikSCAT, ERS, WindSAT, and SSM/I-SSMIS are thinned or "superobbed" (i.e., the creation of "superobservations") to a coarser spacing than their native spatial resolution in the PREPBUFR, thus mitigating the occurrence of lowerquality wind retrievals. Thus, the wind errors at the poles are more likely due to errors in the reanalyses underlying models than to low-quality observations. The reanalyses' AGCM parameterizations may not be sufficiently adjusted to the very particular characteristics of polar meteorology, which are regions of complex interactions between the atmosphere, ocean, and sea ice. Furthermore, there is a scarcity of surface wind observations at the poles such that they might be too few to correct the reanalyses' AGCM solution.

In the middle and low latitudes the errors are clearly lower, except in the intertropical convergence zone (ITCZ) and in the ocean areas surrounding the Indonesian archipelago, where their magnitudes are similar to the midlatitude errors except in the case of the wind direction, where the RMSE values at these locations are considerably higher than at midlatitudes, particularly in the western shores of Central America and equatorial Africa. Chaudhuri et al. (2013) found that the highest surface wind errors in modern reanalyses occur poleward of $40^{\circ}$ in both hemispheres and in the equatorial region near the ITCZ. Given the predominance of ocean wind retrievals by scatterometers in the observational grids and the fact that rain significantly affects them (Carvalho et al. 2013, 2017), it could be argued that the larger errors in the ITCZ and offshore the Indonesian archipelago can be due to the large rain rates typically seen at these latitudes. For the specific case of the Indonesian archipelago, also the fact that these ocean areas are in the vicinity of many islands can account for the errors, since scatterometers have a land footprint of about $20-30 \mathrm{~km}$. However, scatterometer wind retrievals flagged by rain or land contamination tend to be discarded from the observational grids. Thus, the higher errors at these locations are most likely due to errors in the reanalysis models. Nevertheless, satellite-derived winds are representative of the vector difference between the air movement (winds) and the water movement (ocean currents), while conventional observations and model winds are relative to the fixed Earth reference frame. In the tropics, the typical oceanic currents are likely large enough so that the satellite-derived winds may systematically disagree with conventional observations and modeled winds, which can partially account for the differences between the reanalyses and the observational grid winds. In such cases, these differences cannot be solely attributed to reanalysis errors.

Global processes and mechanisms like the ITCZ, trade winds, ocean currents, and SST also have a very strong impact on the surface winds. NWP models usually have higher difficulties in simulating equatorial meteorology due to the complexity of atmospheric circulations, strong convergence, and other mechanisms and processes that occur at low latitudes. Additionally, NWP GCMs parameterizations that are used to represent a wide range of mesoscale meteorological processes are not necessarily adjusted to the particular characteristics of a specific region, as it may be the case for the ITCZ. The ITCZ meteorology is characterized by long episodes of low and dry winds, intercalated with short but powerful storms, and the NWP models that are the basis of the reanalyses may show limitations in accurately representing the timing and magnitude of these short storm episodes. Furthermore, as discussed in Hulst and van Vledder (2013), the reanalyses underlying NWP models do not usually take in consideration ocean currents, which may cause a systematic error in the sea surface temperature that originates errors in the upward vertical fluxes, affecting the horizontal flow toward the ITCZ. This study also reported that outside of the ITCZ an error in the SST seems to cause higher wind errors on the lee side of the continents. This can be seen in the equatorial African and Central American western coasts and also in the eastern coasts of Argentina, the United States, and Asia (Figs. 2 and B1). This type of 
error appears to be mainly directional since it is particularly visible in the wind direction but not so much in the wind speed maps (Fig. 2).

All reanalyses tend to show higher errors, similar in magnitude to the ones seen in the vicinity of the ITCZ, near the western boundary currents such as the Gulf Stream and the Kuroshio system, which agrees with the findings of Wallcraft et al. (2009). Another possible reason for the higher errors seen in the vicinity of the ITCZ is the neutral stability approximation used to extrapolate the buoy winds to $10 \mathrm{~m}$ MSL. In these areas, warmer air can advect over colder ocean water during upwelling events and this may be part of the reason for the typical pattern seen near the ITCZ. The neutral stability approximation can also be partially responsible for the higher errors near the western boundaries of the North Pacific and North Atlantic where, depending on the season, colder or warmer continental air advects over the ocean. However, this effect is harder to see in the results presented because they tend to change sign with the season. In both cases, the higher differences between the reanalyses and observations are not due to the reanalysis winds but to the approximation used to extrapolate the measured winds, since the neutral stability approximation does not hold in the presence of significant thermal gradients between the atmosphereocean surface interface.

Also visible is that ocean areas are much more heavily covered in terms of wind observations than inland ones due to the several spaceborne satellites instruments (scatterometers, microwave radiometers, synthetic aperture radars, etc.) that allow a multitude of surface wind observations over the world oceans but not over inland areas, where there is clearly a strong scarcity and sparsity of surface wind observations. The only observation type that provides inland surface wind observations for the observational grids is from meteorological stations, but this type of wind observations is not usually assimilated in reanalyses because of their high variability and dependency on local topography. However, other observations from land weather stations like the vertical distributions of temperature, relative humidity, and atmospheric pressure are usually assimilated, meaning that near-surface winds from reanalyses are not fully independent from the assimilated observations: through the thermal wind relation that is used to initialize the three-dimensional wind field, near-surface winds will tend to follow observations of other variables. Even so, over land areas the RMSE values tend to be substantially higher, which can be related to the previously mentioned fact that over these areas wind observations are not assimilated. This is to be expected, since by not assimilating wind observations the reanalyses wind values over such areas will tend to be closer to the background wind fields, and thus prone to higher differences when compared with measurements.

Figures 2 and B1 also show that the land areas with lower $U, V$, and wind speed RMSEs are the eastern half of the United States, central Europe, and China. This might be related to the fact that these areas have a relatively dense spatial coverage in terms of meteorological observations that are routinely assimilated by the reanalyses (upper-level rawinsonde winds, temperature, humidity, and pressure), allowing for data selection (quality control and thinning) and multisite observations corrections that can provide a reduction of the observation errors and respective covariance matrices, which will make the reanalyses draw closer to the assimilated observations than to the background. Thus, because of the assimilation of many observations directly related to the wind field, areas where more observations are assimilated (even if not wind ones) will most likely improve the wind field also. However, the Iberian Peninsula, which also has a dense observation network, shows visibly higher errors when compared to the rest of Europe. This can be due to the fact that, in reanalyses with approximately $0.5^{\circ}-0.75^{\circ}$ of horizontal resolution, the Iberian Peninsula is closer to an island/ coastal area than a pure inland one. Such areas are usually characterized by strong temperature gradients, topography, and land use discontinuities, which strongly influence the surface wind field. In these areas, reanalyses tend to show higher errors due to their limited resolution and consequent ability to realistically represent these mesoscale to local-scale flows. This is also the reason why all reanalyses show higher errors in representing the surface wind fields in areas with more varying and complex land-sea topography, such as in the coastal areas around the Indonesian archipelago.

It is also visible that all reanalyses tend to show slightly higher RMSE values along ship routes (Atlantic Ocean, Bay of Bengal, Arabian Sea, South China Sea). Although all reanalyses assimilate ship observations, the reanalysis surface wind fields over most of the open ocean are mainly constrained by assimilated satellite wind retrievals since the amount of this type of observations is several orders of magnitude higher than conventional observations. Thus, along ship routes the reanalyses tend to be closer to satellite wind retrievals than to ship wind measurements, and the differences between the reanalyses and the observational grid, which contain mostly ship wind observations at those grid points, tend to be slightly higher. Also at some grid points scattered in the Pacific and Atlantic Oceans coincident with some TAO/TRITON and PIRATA buoy moorings, the RMSE values are substantially higher. 
This case follows a similar rationale as the one detailed for the ship routes, but exacerbated (the differences between reanalyses and moored buoys are higher than the ones between reanalyses and ship routes) since the reanalyses do not assimilate these winds. At these locations, the reanalysis winds are close to satellite wind retrievals and thus tend to disagree more with the observational grid, which contain mostly buoy measurements at those grid points. (Figures 3 and B2 show similar information as Figs. 2 and B1, but now for the biases.)

According to Fig. 3, practically all reanalyses tend to underestimate the surface wind speed over the oceans, particularly in the Arctic (between $-100^{\circ}$ and $100^{\circ}$ longitude), in the vicinity of the ITCZ, and in the equatorial western coasts of Africa and Central America. This is the case of ERA-I, MERRA, and MERRA2, whereas CFSR and JRA-55 seem to show an opposite tendency at higher latitudes, where the wind speeds are overestimated (except at polar areas). In the continents there is not a clear tendency, but all reanalyses seem to overestimate the surface wind over Europe (an exception is the Iberian Peninsula), Asia, and in the eastern half of the United States. The only exception is JRA-55, which seems to have an overall tendency to underestimate the wind speed over practically all land areas (except at some locations scattered across the United States and Asia). As for the wind direction biases, all reanalyses seem to represent the wind direction rotated clockwise in the Northern Hemisphere (positive bias) and anticlockwise in the Southern Hemisphere (negative bias). The exception is JRA-55, which seems to show positive directional biases globally, although they are lower than the ones from the other reanalyses.

In looking at Fig. B2, it is seen that the most striking feature is that the $U$ wind component seems to be overestimated by all reanalyses over ocean areas, with some localized exceptions where it is underestimated (mainly around the Indonesian archipelago and the western coasts of Africa and Central America). Still in ocean areas, the $V$ wind component shows a clear distinction between the Northern and Southern Hemispheres: all reanalyses overestimate it in the Northern Hemisphere (except at the pole and ITCZ), and underestimate it in the Southern Hemisphere (with some exceptions such as the western coasts of South Africa and South America). Thus, all reanalyses tend to depict the surface winds too eastward globally, too northward in the Northern Hemisphere, and too southward in the Southern Hemisphere. Over land regions, a clear tendency is not discernible, with some areas showing an overestimation while other areas show an underestimation of the wind vectorial components.
Figure 4 (wind speed and direction) and Fig. B3 ( $U$ and $V$; available in appendix B) show global maps of the RMSE differences between MERRA-2 and the other reanalyses.

For the wind speed and direction MERRA-2 shows lower RMSE values than CFSR and MERRA over practically all the world oceans, but higher than the JRA-55 and ERA-I in the tropics (particularly for the wind speed). Over land, MERRA-2 does not seem to show a clear tendency for higher or lower errors when compared to CFSR and MERRA. However, when compared with ERA-I or JRA-55, MERRA-2 seems to show overall higher errors. Globally, ERA-I surface winds seem to be ones with lowest RMSE values, while CFSR seems to have the highest ones. This might be related to the fact that, as previously mentioned, CFSR 0000, 0600, 1200, and 1800 UTC 10-m winds are 6-h forecasts and thus prone to higher differences when compared with observations.

The RMSE differences between MERRA-2 and the other reanalyses are usually below $0.5 \mathrm{~m} \mathrm{~s}^{-1}$ for the wind speed and $U$ and $V$ components (Fig. B3), and $5^{\circ}-7^{\circ}$ for the wind direction, which are relatively low values and can be explained by the fact that all reanalyses assimilate practically the same observations. However, MERRA-2 is the one that assimilates more ocean surface wind observation types: besides QuikSCAT and $E R S-1 / 2$ like all other reanalyses, MERRA-2 also assimilates ASCAT ocean wind vectors (JRA-55 also), WindSAT (CFSR also, but only after 2008), SSM/I, and SSMIS wind speeds.

The same patterns are seen in Fig. B3 ( $U$ and $V$ wind components' RMSE differences): MERRA-2 shows lower RMSEs than CFSR and MERRA over practically all the world oceans, but higher than JRA-55 and ERA-I, particularly for the $V$ component of the wind in the tropics. Over land, the $U$ and $V$ error differences are similar to the ones seen for the wind speed and direction: neutral spatial differences when compared to CFSR and MERRA but higher errors when compared with ERA-I and JRA-55.

For $U, V$, wind speed, and direction, it is clear that MERRA-2 surface winds show the lowest errors at polar areas. This can be related to the fact that MERRA-2 is the reanalysis that assimilates more polar wind measurements, mainly 3D atmospheric motion vectors (AMVs). ERA-I does not assimilate any source of polar AMVs, while CFSR, JRA-55, and MERRA only assimilate NASA's Moderate Resolution Imaging Spectroradiometer (MODIS) AMVs on board NASA's polar orbiters Aqua and Terra, since MERRA assimilates MODIS winds starting from 2002 whereas CFSR and JRA-55 only assimilate MODIS winds starting in 

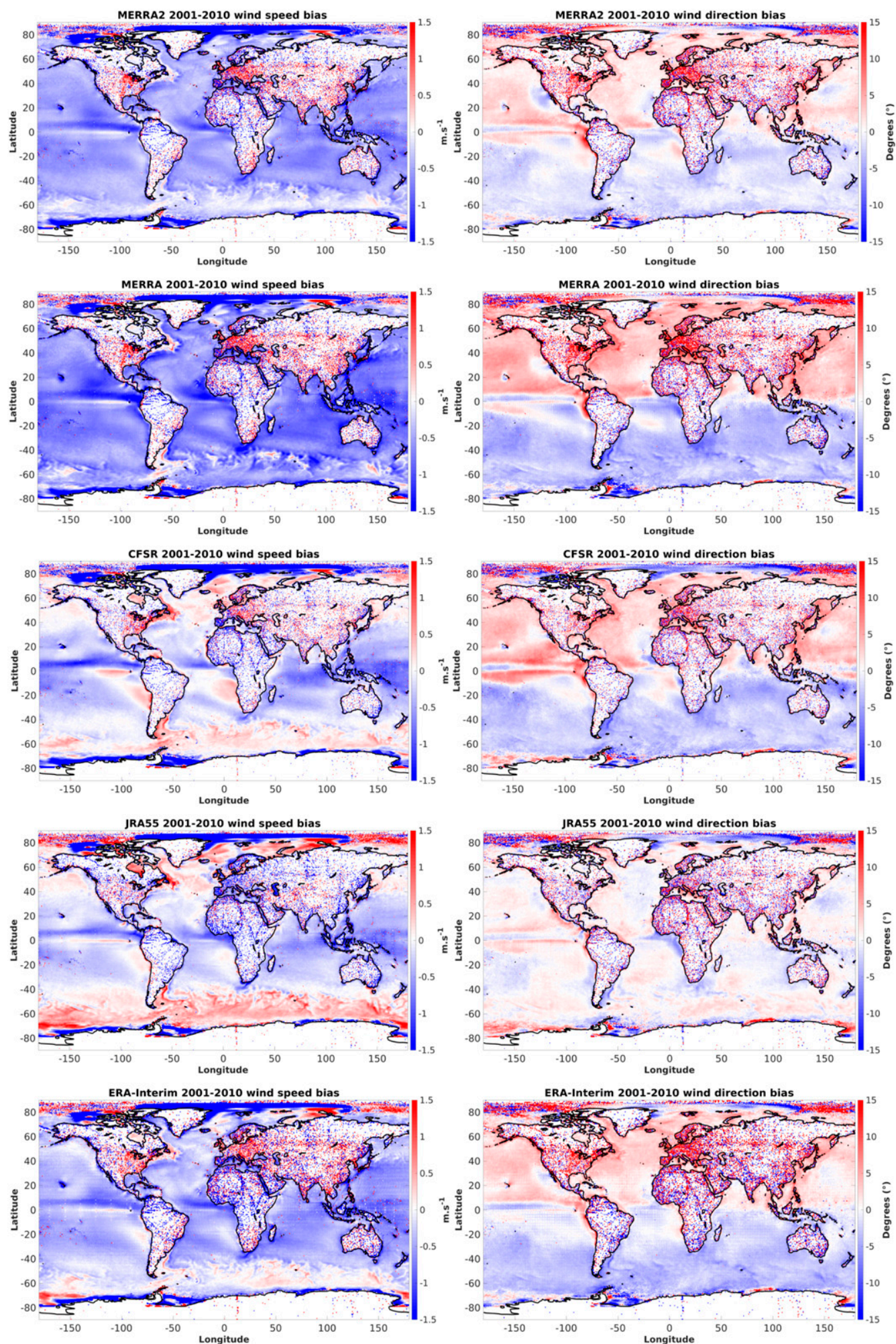

FIG. 3. Wind speed and direction global bias maps for the 2001-10 period. 

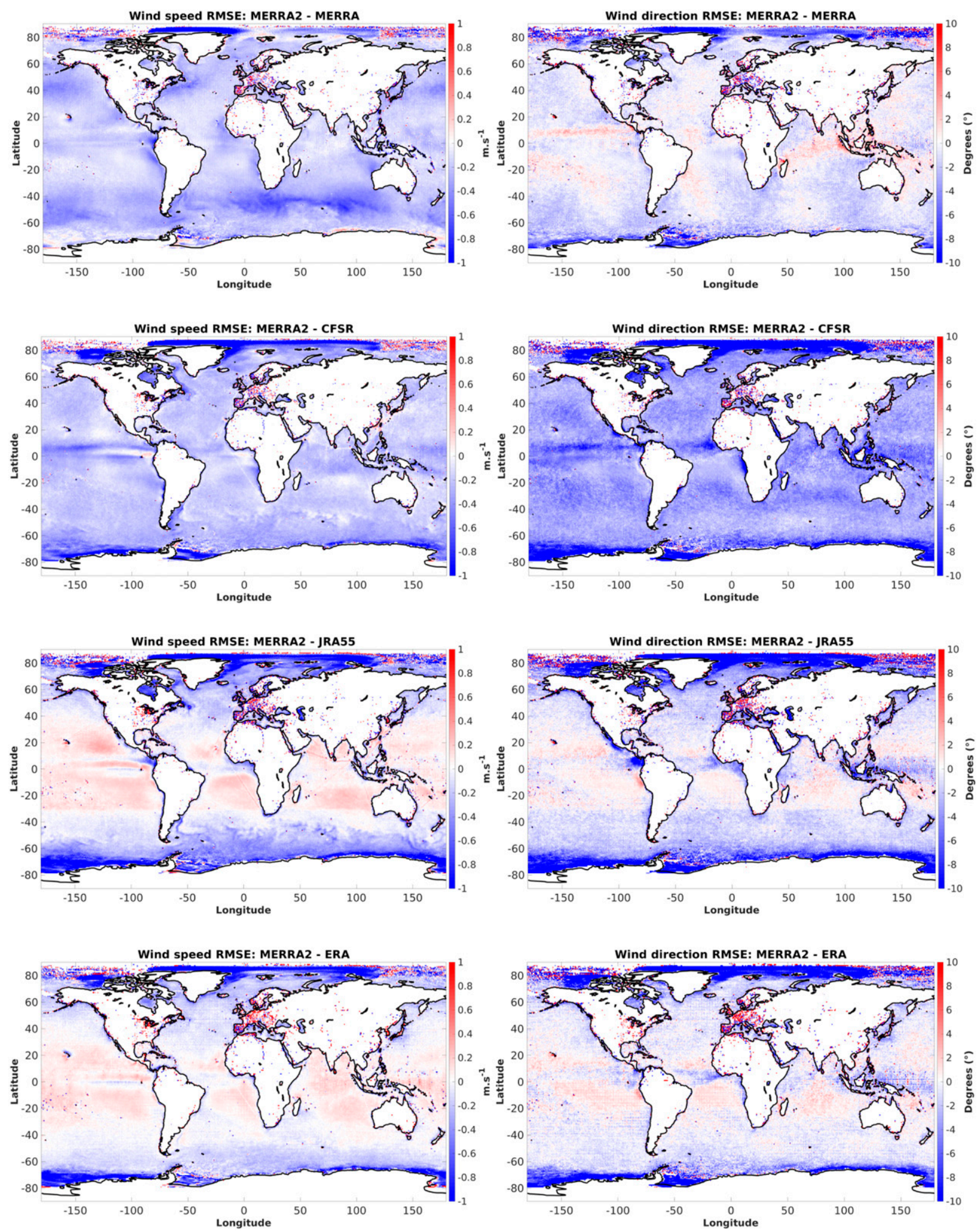

FIG. 4. Wind speed and direction global RMSE difference for the 2001-10 period. 
2004. MERRA-2, in addition to MODIS polar winds starting in 2002, also assimilates polar AMVs retrieved by the NOAA/EUMETSAT Advanced Very High Resolution Radiometer (AVHRR) starting in 1982. Although AMVs are not surface wind observations, showing vertical distributions that resemble a bimodal distribution with observation counts maxima located at $\sim 200-300$ and $\sim 900-800 \mathrm{hPa}$, the latter is relatively close to the surface (see, e.g., Lean et al. 2015). Thus, the assimilation of a large amount of wind observations close(r) to the surface most likely contributes to the improvement of the representation of the near-surface wind fields in the reanalyses.

A final aspect to take into account is the long-term stability of the reanalyses wind data since all of the results presented in this work consist of wind data from reanalyses and observations for the period 2001-10 only. Although a complete decade of wind data can be considered a large enough sample to draw solid conclusions, it could be argued that these results could vary upon the choice of a different time period, especially when the reanalyses cover periods of 37-55 years. To assess the long-term stability of the reanalyses' nearsurface wind fields, approximately 35 years of in situ wind observations from two of the TAO/TRITON array buoys (the ones with the longest periods of operation) and simultaneous wind data from all reanalyses were plotted as time series. (Figures $\mathrm{C} 1$ and $\mathrm{C} 2$, in appendix $\mathrm{C}$, show the buoys' and reanalyses' wind time series comparisons in terms of monthly means.) For both buoys, all reanalyses show similar time series for the time period between the early 1980s and late 2010s, and no major differences are detectable between the 2001-10 period and the other ones. Therefore, the reanalyses' wind fields show long-term stability.

Overall, the results presented in this work suggest that MERRA-2 surface wind fields represent a clear improvement over MERRA and are comparable with the other modern reanalyses in terms of an accurate representation of the global near-surface wind fields. Although the differences among all reanalyses are relatively small, the reanalyses that employ $4 \mathrm{D}-\mathrm{Var}$ (ERA-I and JRA-55) seem to show globally lower overall errors when compared with the ones that still use a 3D-Var formulation. This is particularly the case of ERA-I, which showed the lowest overall errors in a global perspective.

Besides the type of variational scheme used, there are other important differences between these reanalyses that might contribute to the superiority of ERA-I surface wind fields. While ERA-Interim (and JRA-55) surface wind fields are fully analyzed, CFSR ones consist of pure 1-6-h forecasts (the files corresponding to the $0000,0600,1200$, and 1800 UTC are actually $6-\mathrm{h}$ forecasts). MERRA and MERRA2 ones, although not fully analyzed, use IAU to keep the fields close to the analysis increments. In this sense, IAU can be seen as a kind of middle step between an analysis and a forecast. Additionally, only ERA-I analyzes surface waves, which closely interact with ocean surface winds affecting the roughness and drag coefficient and can contribute to a better representation of the ocean surface wind fields. Last, ERA-I's first vertical level is located at approximately $10 \mathrm{~m}$ above the surface, while for JRA-55 the first vertical level is located at approximately at $125-\mathrm{m}$ height. CFSR's first vertical model level is located at around 30-m height, and for MERRA/MERRA2 it is at approximately $90-\mathrm{m}$ height. Thus, the increased vertical resolution of ERA-I near the surface is most likely an important advantage to accurately depict the global surface wind fields.

Modern reanalyses assimilate millions of observations each 6-h cycle, and this number is expected to increase in future reanalyses. Thus, there is a substantial difficulty in finding independent observations (i.e., not used in the assimilation) that can be used as validation reference, and this difficulty will also most likely increase in the near future. However, it should be borne in mind that the use of independent observations is crucial to obtain reliable validation results. Reanalyses' error metrics at locations/times where observations were directly assimilated cannot be generalized in a straightforward way to other areas/times where no observations were assimilated. Before making use of reanalyses, care is also necessary in knowing exactly what each reanalysis data type is and means. As referenced in this study, variables in reanalyses can be made available as fully reanalyzed fields, pure forecasts, or as a combination of both. If such aspects are not taken into consideration by the users, results and findings can become severely flawed and misleading.

\section{Conclusions}

The quality of MERRA-2 surface wind fields was assessed by comparing them with a wide range of surface wind observing platforms. This assessment includes a comparison of MERRA-2 global surface wind fields with the ones from its predecessor MERRA to assess whether GMAO's latest reanalyses improved the representation of the global surface winds. At the same time, surface wind fields from other modern reanalyses, NCEP-CFSR, ERA-Interim, and JRA-55, were also included in the comparisons to evaluate MERRA-2 global surface wind fields in the context of its contemporary reanalyses. 


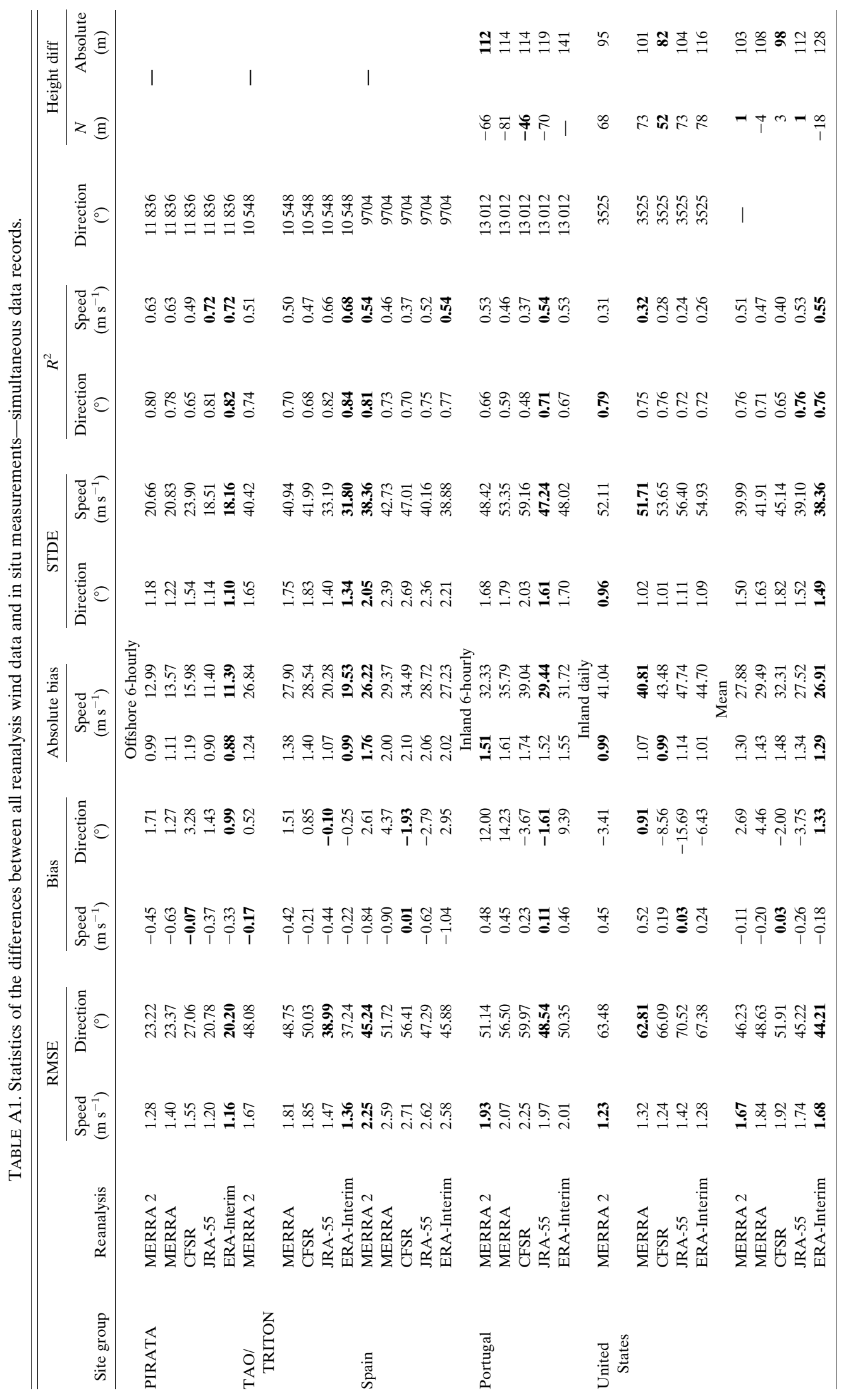





FIG. B1. The $U$ and $V$ wind components' global RMSE maps for the 2001-10 period. 

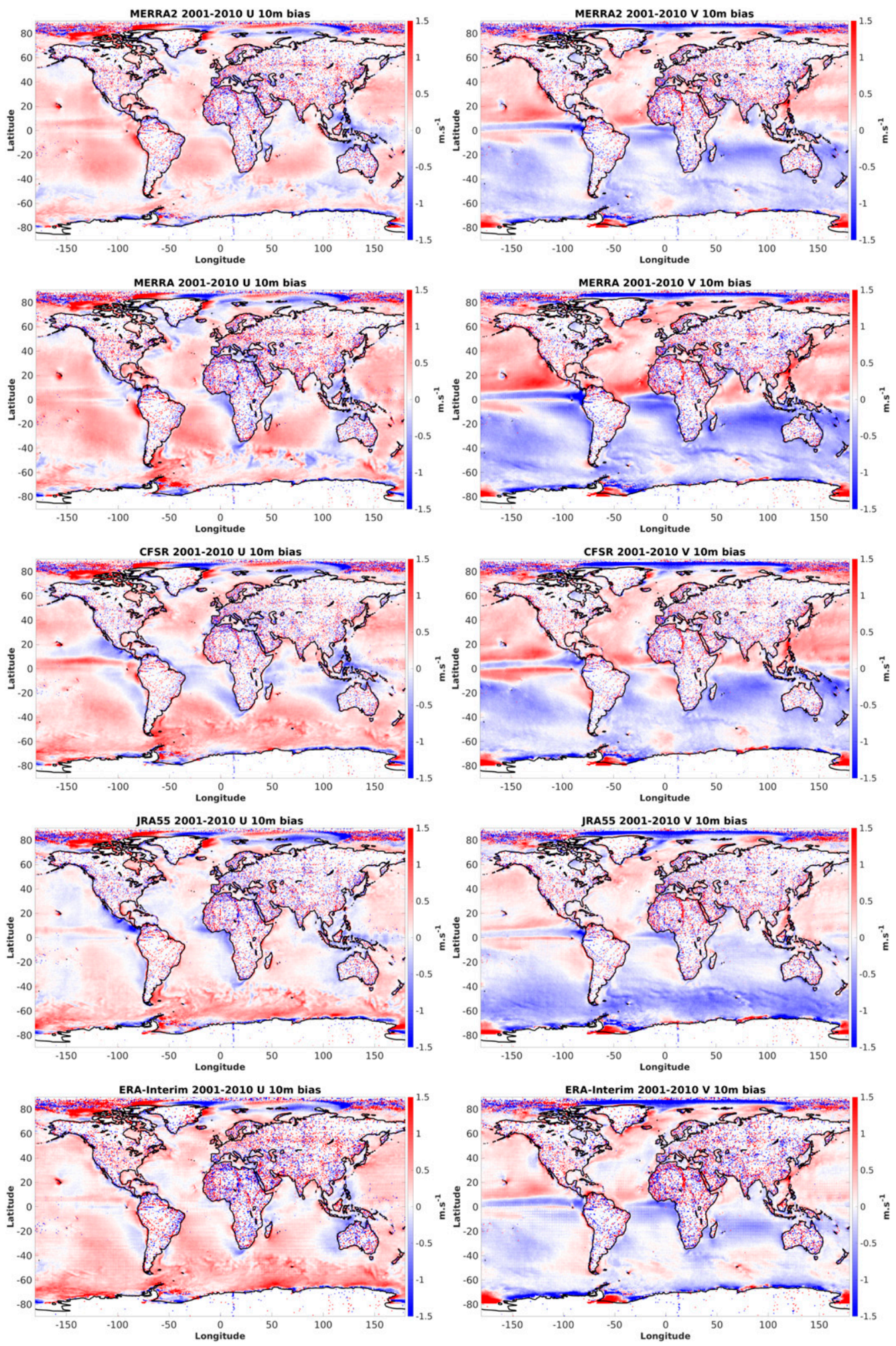

FIG. B2. The $U$ and $V$ wind components' global bias maps for the 2001-10 period. 

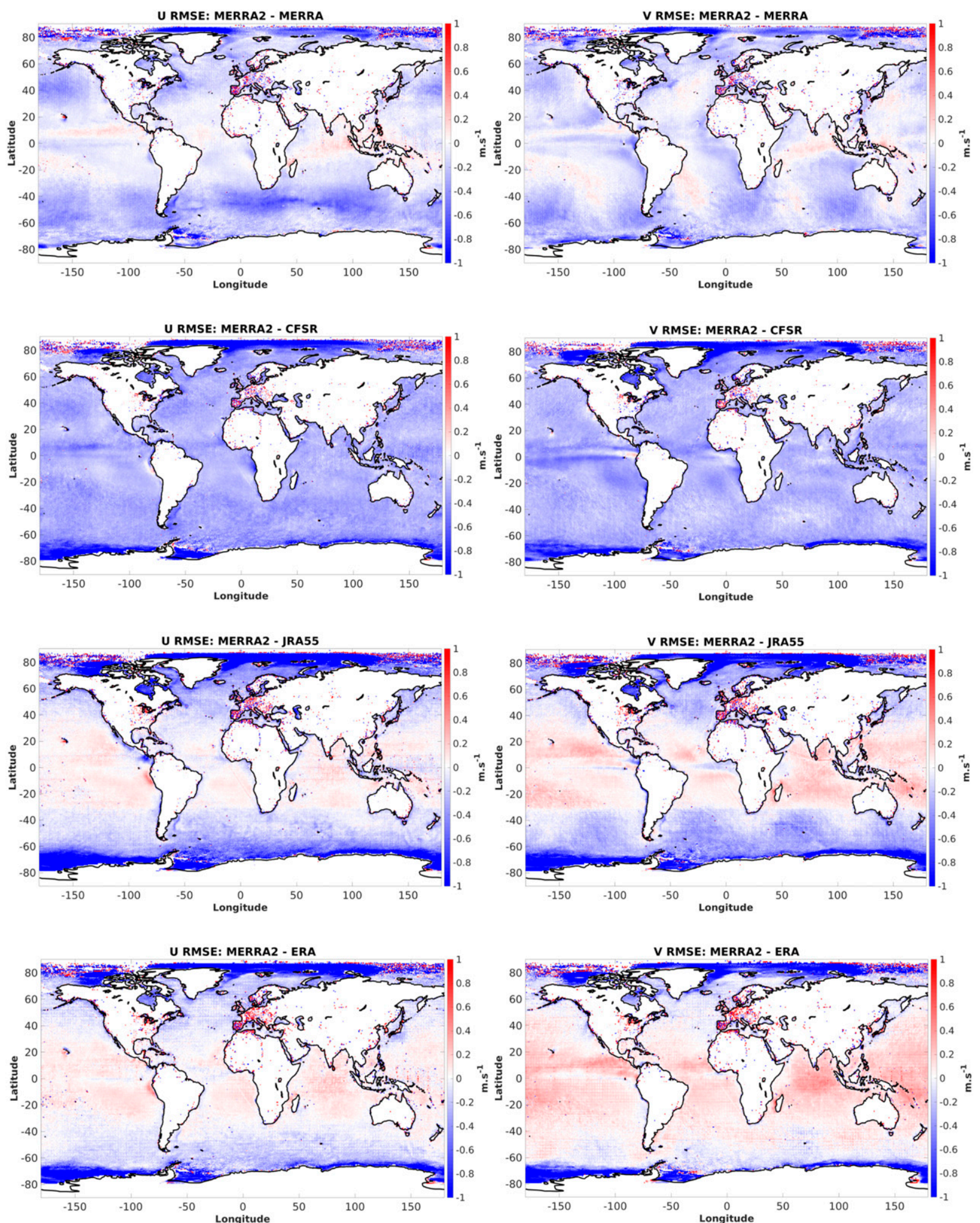

FIG. B3. The $U$ and $V$ wind components' global RMSE difference for the 2001-10 period. 


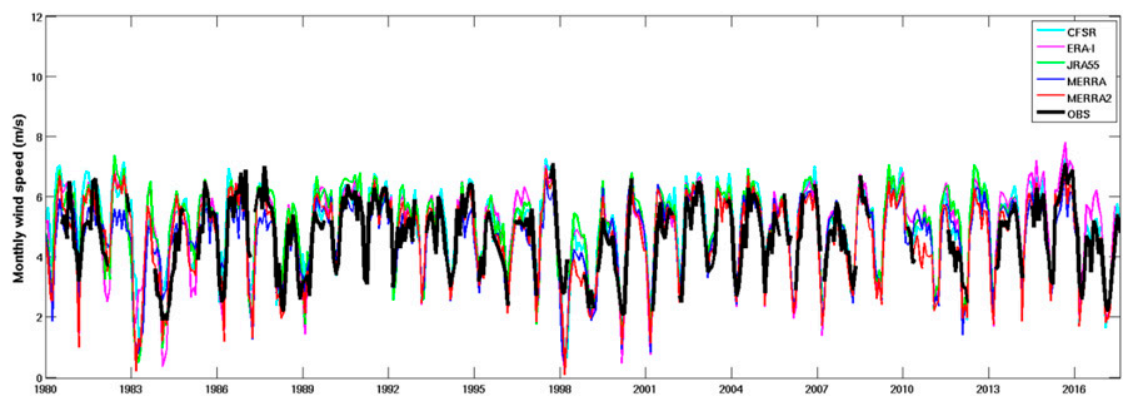

FIG. C1. Long-term wind speed time series: Buoy TAO/TRITON 1.

First, the reanalysis wind data were compared with 10 years of in situ wind measurements taken at almost 100 land and ocean sites. Afterward, a global 10-yr, 6-hourly, observational grid was built using a wide range of observational platforms as data types and wind data from the several reanalyses were compared with this observational grid. The results presented here showed that MERRA-2, CFSR, ERA-I, and JRA-55 show similar error metrics, with ERA-Interim showing the lowest overall errors and MERRA the highest ones. Thus, MERRA-2 surface wind field accuracy represents a clear improvement to its predecessor, MERRA, and is in line with the other contemporary reanalyses.

All reanalyses tend to underestimate ocean surface winds (particularly in the tropics) and, oppositely, to overestimate inland surface winds (except JRA-55, which showed a global tendency to underestimate the wind speeds). They also seem to represent the wind direction rotated clockwise in the Northern Hemisphere (positive bias) and anticlockwise in the Southern Hemisphere (negative bias). In terms of wind vectorial components, all reanalyses showed a tendency to represent the surface winds too eastward globally, too northward in the Northern Hemisphere, and too southward in the Southern Hemisphere, particularly over ocean areas.

The spatial patterns and variations of the errors were similar among all reanalyses, given their similar physical assumptions, limitations, and assimilation of common observations. All reanalyses showed higher errors at coastal and land areas, while the errors were considerably lower in the open ocean. Additionally, all reanalyses showed higher errors near the poles and in the ITCZ, particularly in the equatorial western coasts of Central America and Africa. However, MERRA-2 showed substantially lower wind errors in the poles when compared with the other reanalyses, which might be related to the fact that this reanalysis assimilates unique polar wind observations that are not assimilated by any of the other reanalyses.

Acknowledgments. Funding for this work was provided by the NASA Modeling, Analysis, and Prediction program. Computational resources were provided by the NASA High-End Computing Program through the NASA Center for Climate Simulation. The authors acknowledge the teams that provided the reanalysis data (ECMWF, NCEP, JRA, and GMAO) and the observational data used here: Puertos del Estado (Spain), Aveiro University (Portugal), NCEP, and NOAA's Pacific Marine Environmental Laboratory (PMEL). Acknowledgments are also given to Santha Akella, Meta Sienkiewicz, and Ron Errico (GMAO) for providing valuable information and insight to this work. The authors also thank the anonymous reviewers whose valuable suggestions and discussions greatly improved the present study.

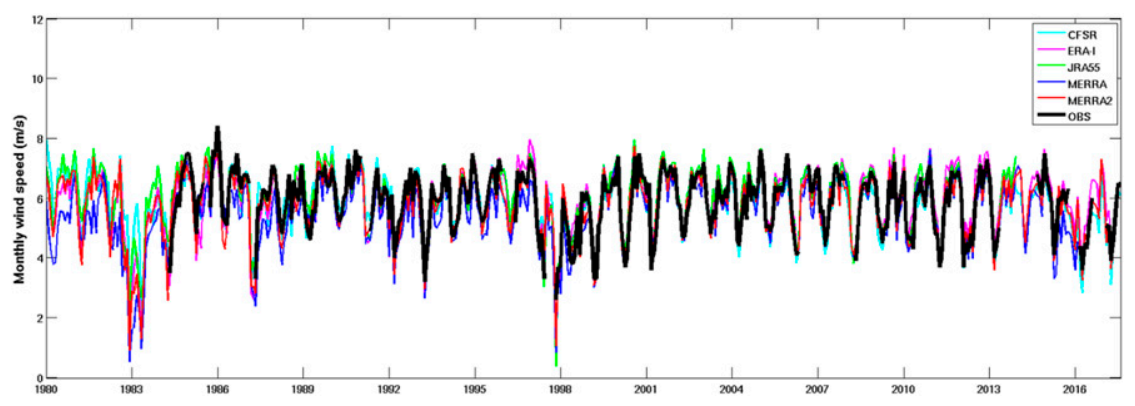

FIG. C2. Long-term wind speed time series: Buoy TAO/TRITON 2. 


\section{APPENDIX A}

\section{Comparison of Reanalysis Winds and In Situ Measurements-Simultaneous Records Only}

Table A1 shows a comparison, for temporally simultaneous data records at 6-hourly resolution, of differences between reanalysis winds and in situ observations.

\section{APPENDIX B}

\section{Global Statistics for $\boldsymbol{U}$ and $\boldsymbol{V}$ Wind Components}

Figures B1-B3 are similar to Figs. 2-4, but respectively give the RMSE, bias, and RMSE difference for the $U$ and $V$ components of the wind over the globe.

\section{APPENDIX C}

\section{Long-Term Comparison of Winds from Reanalyses and Buoys}

Figures $\mathrm{C} 1$ and $\mathrm{C} 2$ show an approximately 35 -yr times series to allow comparison of wind speeds from reanalyses with buoy observations.

\section{REFERENCES}

Alvarez, I., M. M. Gomez-Gesteira, M. deCastro, and D. Carvalho, 2014: Comparison of different wind products and buoy wind data with seasonality and interannual climate variability in the southern Bay of Biscay (2000-2009). Deep-Sea Res. II, 106, 38-48, https://doi.org/10.1016/j.dsr2.2013.09.028.

Bloom, S. C., L. L. Takacs, A. M. da Silva, and D. Ledvina, 1996: Data assimilation using incremental analysis updates. Mon. Wea. Rev., 124, 1256-1271, https://doi.org/10.1175/15200493(1996)124<1256:DAUIAU > 2.0.CO;2.

Bosilovich, M. G., F. R. Robertson, and J. Chen, 2011: Global energy and water budgets in MERRA. J. Climate, 24, 57215739, https://doi.org/10.1175/2011JCLI4175.1.

— J.-D. Chern, D. Mocko, F. R. Robertson, and A. M. da Silva, 2015: Evaluating observation influence on regional water budgets in reanalyses. J. Climate, 28, 3631-3649, https:// doi.org/10.1175/JCLI-D-14-00623.1.

Bourassa, M. A., D. M. Legler, J. J. O'Brien, and S. R. Smith, 2003: SeaWinds validation with research vessels. J. Geophys. Res., 108, 3019, https://doi.org/10.1029/2001JC001028.

Carvalho, D., A. Rocha, M. Gómez-Gesteira, and C. Silva Santos, 2013: Comparison between CCMP, QuikSCAT and buoy winds along the Iberian Peninsula coast. Remote Sens. Environ., 137, 173-183, https://doi.org/10.1016/j.rse.2013.06.005.

,,--- , and,$- 2014 \mathrm{a}$ : Comparison of reanalyzed, analyzed, satellite-retrieved and NWP modelled winds with buoy data along the Iberian Peninsula coast. Remote Sens. Environ., 152, 480-492, https://doi.org/10.1016/j.rse.2014.07.017.

,,,--- and,$- 2014 \mathrm{~b}$ : WRF wind simulation and wind energy production estimates forced by different reanalyses:
Comparison with observed data for Portugal. Appl. Energy, 117, 116-126, https://doi.org/10.1016/j.apenergy.2013.12.001.

,,--- , and,$- 2014 \mathrm{c}$ : Offshore wind energy resource simulation forced by different reanalyses: Comparison with observed data in the Iberian Peninsula. Appl. Energy, 134, 5764, https://doi.org/10.1016/j.apenergy.2014.08.018.

$-, \ldots, \ldots$, and $—, 2017$ : Offshore winds and wind energy production estimates derived from ASCAT, OSCAT, numerical weather prediction models and buoys-A comparative study for the Iberian Peninsula Atlantic coast. Renewable Energy, 102B, 433-444, https://doi.org/10.1016/ J.RENENE.2016.10.063.

Chaudhuri, A. H., R. M. Ponte, G. Forget, and P. Heimbach, 2013: A comparison of atmospheric reanalysis surface products over the ocean and implications for uncertainties in air-sea boundary forcing. J. Climate, 26, 153-170, https://doi.org/ 10.1175/JCLI-D-12-00090.1.

,,-- and A. T. Nguyen, 2014: A comparison of atmospheric reanalysis products for the Arctic Ocean and implications for uncertainties in air-sea fluxes. J. Climate, 27, 5411-5421, https://doi.org/10.1175/JCLI-D-13-00424.1.

Chelton, D. B., and M. H. Freilich, 2005: Scatterometer-based assessment of $10-\mathrm{m}$ wind analyses from the operational ECMWF and NCEP numerical weather prediction models. Mon. Wea. Rev., 133, 409-429, https://doi.org/10.1175/ MWR-2861.1.

Decker, M., M. A. Brunke, Z. Wang, K. Sakaguchi, X. Zeng, and M. G. Bosilovich, 2011: Evaluation of the reanalysis products from GSFC, NCEP, and ECMWF using flux tower observations. J. Climate, 25, 1916-1944, https://doi.org/10.1175/JCLID-11-00004.1.

Dee, D. P., and Coauthors, 2011: The ERA-Interim reanalysis: Configuration and performance of the data assimilation system. Quart. J. Roy. Meteor. Soc., 137, 553-597, https://doi.org/ 10.1002/qj.828.

Fisher, N. I., 1995: Statistical Analysis of Circular Data. Cambridge University Press, 277 pp.

Francis, J. A., 2002: Validation of reanalysis upper-level winds in the Arctic with independent rawinsonde data. Geophys. Res. Lett., 29, 1315, https://doi.org/10.1029/2001GL014578.

Friedrich, L. S., A. J. McDonald, G. E. Bodeker, E. C. Kathy, J. Lewis, and A. J. Paterson, 2017: A comparison of Loon balloon observations and stratospheric reanalysis products. Atmos. Chem. Phys., 17, 855-866, https://doi.org/10.5194/acp17-855-2017.

Gelaro, R., and Coauthors, 2017: The Modern-Era Retrospective Analysis for Research and Applications, version 2 (MERRA-2). J. Climate, 30, 5419-5454, https://doi.org/10.1175/JCLI-D-16-0758.1.

Hoffmann, L., A. Hertzog, T. Rößler, O. Stein, and X. Wu, 2017: Intercomparison of meteorological analyses and trajectories in the Antarctic lower stratosphere with Concordiasi superpressure balloon observations. Atmos. Chem. Phys., 17, 80458061, https://doi.org/10.5194/acp-17-8045-2017.

Hulst, S., and G. P. van Vledder, 2013: CFSR surface wind calibration for wave modelling purposes. 13th Int. Workshop on Wave Hindcasting and Forecasting and Coastal Hazards Symp., Banff, AB, Canada, Environment Canada, http:// waveworkshop.org/13thWaves/Papers/2013_CFSR_10m_wind_ calibration.pdf.

Jammalamadaka, S. R., and A. SenGupta, 2001: Topics in Circular Statistics. World Scientific, 336 pp.

Kalnay, E., 2003: Atmospheric Modeling, Data Assimilation and Predictability. Cambridge University Press, $341 \mathrm{pp}$. 
Kara, A. B., A. J. Wallcraft, and M. A. Bourassa, 2008: Air-sea stability effects on the $10 \mathrm{~m}$ winds over the global ocean: Evaluations of air-sea flux algorithms. J. Geophys. Res., 113, C04009, https://doi.org/10.1029/2007JC004324.

Kobayashi, S., and Coauthors, 2015: The JRA-55 reanalysis: General specifications and basic characteristics. J. Meteor. Soc. Japan, 93, 5-48, https://doi.org/10.2151/jmsj.2015-001.

Lean, P., S. Migliorini, and G. Kelly, 2015: Understanding atmospheric motion vector vertical representativity using a simulation study and first-guess departure statistics. J. Appl. Meteor. Climatol., 54, 2479-2500, https://doi.org/10.1175/ JAMC-D-15-0030.1.

Liu, W. T., and W. Tang, 1996: Equivalent neutral wind. California Institute of Technology Jet Propulsion Laboratory Publ. 96$17,22 \mathrm{pp}$.

Manney, G. L., and Coauthors, 2017: Reanalysis comparisons of upper tropospheric-lower stratospheric jets and multiple tropopauses. Atmos. Chem. Phys., 17, 11541-11566, https:// doi.org/10.5194/acp-17-11541-2017.

McCarty, W., L. Coy, R. Gelaro, A. Huang, D. Merkova, E. B. Smith, M. Seinkiewicz, and K. Wargan, 2016: MERRA-2 input observations: Summary and assessment. NASA Rep. NASA/ TM-2016-104606, Vol. 46, 61 pp.

Mears, C. A., D. K. Smith, and F. J. Wentz, 2001: Comparison of Special Sensor Microwave Imager and buoy-measured wind speeds from 1987 to 1997. J. Geophys. Res., 106, 11 719-11 729, https://doi.org/10.1029/1999JC000097.

Molod, A., L. Takacs, M. Suarez, and J. Bacmeister, 2015: Development of the GEOS-5 atmospheric general circulation model: Evolution from MERRA to MERRA-2. Geosci.
Model Dev., 8, 1339-1356, https://doi.org/10.5194/gmd-8-13392015

Monin, A. S., and A. M. Obukhov, 1954: Osnovnye zakonomernosti turbulentnogo peremeshivanija $\mathrm{v}$ prizemnom sloe atmosfery (Basic laws of turbulent mixing in the atmosphere near the ground). Tr. Geofiz. Inst. AN SSSR, 24, 163-187.

Reichle, R. H., R. D. Koster, G. J. M. De Lannoy, B. A. Forman, Q. Liu, S. Mahanama, and A. Touré, 2011: Assessment and enhancement of MERRA land surface hydrology estimates. J. Climate, 24, 6322-6338, https://doi.org/10.1175/JCLI-D-1005033.1.

Rienecker, M. M., and Coauthors, 2008: The GEOS-5 Data Assimilation System-Documentation of versions 5.0.1, 5.1.0, and 5.2.0. NASA Tech. Rep. NASA/TM-2008-104606, Vol. 27, 118 pp., https://gmao.gsfc.nasa.gov/pubs/docs/Rienecker369.pdf.

— rospective Analysis for Research and Applications. J. Climate, 24, 3624-3648, https://doi.org/10.1175/JCLI-D-11-00015.1.

Robertson, F. R., M. G. Bosilovich, J. Chen, and T. L. Miller, 2011: The effect of satellite observing system changes on MERRA water and energy fluxes. J. Climate, 24, 5197-5217, https:// doi.org/10.1175/2011JCLI4227.1.

Saha, S., and Coauthors, 2010: The NCEP Climate Forecast System Reanalysis. Bull. Amer. Meteor. Soc., 91, 1015-1057, https:// doi.org/10.1175/2010BAMS3001.1.

Wallcraft, A. J., A. B. Kara, C. N. Barron, E. J. Metzger, R. L. Pauley, and M. A. Bourassa, 2009: Comparisons of monthly mean 10-m wind speeds from satellites and NWP products over the global ocean. J. Geophys. Res., 114, D16109, https:// doi.org/10.1029/2008JD011696. 